GIBSON, E. J., BERGMAN, R., \& PURDY, J. The effect of prior training, with a scale of distance on absolute and relative judgments of distance over ground. Journal of Experimental Psychology, 1955, 50, 97-105.

GILINSKY, A. S. Perceived size and distance in visual space. Psychological Review, 1951, 58, 460-482.

GRAHAM, C. H. Visual space perception. In C. H Graham (Ed.), Vision and visual perception. New York: Wiley, 1966.

HARWAY, N. I. Judgment of distance in children and adults. Journal of Experimental Psychology, 1963, 65, 385-390.

KÜNNAPAS, T. Scales for subjective distance. Scandinavian Journal of Psychology, 1960, 1 , 187-192.

LURIA, S. M., KINNEY, J. A. S., \& WEISSMAN, S. Distance estimates with "filled" and "unfilled" space. Perceptual \& Motor Skills, $1967,24,1007-1010$.
PURDY, J., \& GIBSON, E. J. Distance judgment by the method of fractionation. Journal of Experimental Psychology, 1955, 50, 374-380.

STERNBERG, S. Four theories of the effect of distance on apparent size. Paper presented at a meeting of the Psychonomic Society, 1966.

TEGHTSOONIAN, M., \& TEGHTSOONIAN, R. Size constancy: Magnitude estimations as functions of stimulus area and distance. Paper presented at a meeting of the Eastern Psychological Association, 1966.

NOTE

1. We thank Sandra Eber, who ran Ss for Experiment 1, and Eleanor Oldach, who ran Ss for Experiment 2 .

\title{
Anxiety and volunteering
}

JOHN C. BAREFOOT, Dartmouth College, Hanover, N.H.03755

It was suggested that the relationship between anxiety and volunteering might best be studied using an anxiety scale which is not clinically oriented, such as the Activity Preference Questionnaire (APQ). Anxiety levels of introductory psychology students were assessed using the $A P Q$ and the Taylor Manifest Anxiety Scale(TMAS). $A P Q$ scores were significantly related to the tendency to volunteer for psychological experiments. High anxious Ss participated in more experiments than did moderate or low anxious Ss. TMAS scores were not related to experimental participation.

Since psychological research is often based on data obtained from volunteer Ss, the generality of many studies is dependent on the representativeness of volunteer samples. Several studies have investigated the characteristics of volunteers(Bell, 1962; Rosenthal, 1965), but the findings have not always fit into a coherent pattern. Attempts to discover a relationship between anxiety and the tendency to volunteer have yielded particularly confusing results. Scheier (1959), using the IPAT anxiety scale, found that volunteers for a study of anxiety were less anxious than nonvolunteers. Rosen (1951) and Schubert (1964), using the MMPI Pt (psychasthenia) scale, found volunteers to have higher anxiety than nonvolunteers. Martin \& Marcuse (1958) asked students to volunteer for experiments on several topics and compared their Taylor Manifest Anxiety Scale (TMAS) scores with the scores of nonvolunteers. While they found no differences between volunteers and nonvolunteers if the experiments were concerned with learning or sex attitudes, volunteers for a personality experiment were higher in anxiety than nonvolunteers. Heilizer (1960), Himelstein (1956), Howe (1960), and Seigman (1956) report no relationship between TMAS scores and the tendency to volunteer.

As Bell (1962) has suggested, clinically-oriented tests may not be the most relevant measuring instruments for a normal population. Tests which are not based on the self-report of pathological symptoms might therefore be useful in studies of volunteering. Lykken (1957) has devised an anxiety scale, the Activity Preference Questionnaire (APQ), which meets this criterion. The present study was designed to test the relationship between $A P Q$ scores and the tendency to volunteer.

The short form of the APQ consists of 33 forced-choice items, each listing two rather unpleasant activities. The $S$ is asked to choose the activity which he would prefer. One of the alternatives is unpleasant because of its anxiety-arousing nature (e.g., "Being interviewed for a job"), while the other is not anxiety-arousing, but is unpleasant because of its onerous nature (e.g., "Washing the dinner dishes"). Presumably, those people who are most subject to anxiety should choose fewer of the anxiety-arousing alternatives. The APQ has been shown to predict performance on an avoidance task in which learning is facilitated by fear (Lykken, 1957; Schachter \& Latané, 1964), the degree of disturbance of rescue workers at the scene of a disaster (Latane \& Wheeler, 1967), and self-reports of nervousness during a psychological experiment (Barefoot, 1967). In addition, the scale has distinguished sociopathic prisoners from normals (Lykken, 1957; Schachter \& Latané, 1964). Interestingly, Valins (1967) has also shown that those Ss identified by the APQ as low anxious are less likely to keep appointments to participate in an experiment than are highly anxious Ss.

In the present study, the volunteering act was defined so as to be relevant to a wide variety of laboratory experimentation. APQ and TMAS scores of introductory psychology students were compared to the number of experiments in which each student participated during the term.

\section{METHOD}

Data were obtained from three classes of introductory psychology at Dartmouth College, 1967 Fall term, 1968 Spring term, and 1969 Winter term. The tendency to volunteer was defined as the number of experiments in which each student participated during the term. At Dartmouth, introductory psychology students have the opportunity to participate in a variety of experiments, but there is no course requirement that they do so. They can gain some course credit by their participation, however. Most students were freshmen or sophomores, and no females were included in the samples.

Each student's score on the Taylor Manifest Anxiety Scale (Taylor, 1953) was obtained from his responses to the MMPI, which is administered to all entering Dartmouth freshmen. TMAS scores were available for $95 \%$ of the students enrolled in the classes which were studied.

The methods of administering the APQ (Lykken, 1957) differed between the three terms. In the Fall term, 1967, all students were asked to complete the APQ during the regular class period. Scores were obtained for $90.8 \%$ of the students enrolled in the course. In the 1968 and 1969 terms, students did not fill out the scale during the regular class period, but during a "general testing session" for which the students volunteered and received the usual experimental credit. Additional scores were obtained during the 1969 term from students who participated in two unrelated experiments. APQ scores were obtained from $43.7 \%$ of those enrolled in the 1968 term and $57.3 \%$ of those enrolled during the 1969 term.

\section{RESULTS}

The correlation between APQ and TMAS scores (all samples combined) is -.07 , a result which is in line with previous research on these scales (Lykken \& Katzenmeyer, 1968).

Since the opportunities for volunteering varied between terms, the three samples cannot be pooled and they were treated as replications.

TMAS as a Predictor of Volunteering

Students in each sample were divided into high-, moderate-, and low-anxiety categories on the basis of their responses to the TMAS. High-anxious Ss had scores of 21 or greater while low-anxious Ss had scores of 7 or less. These criteria were identified by Taylor (1953) as the 80th and 20th percentiles of 
Table 1

TMAS Category and Mean Experimental Participation

\begin{tabular}{lcccr}
\hline & \multicolumn{4}{c}{ Anxiety Level } \\
\cline { 2 - 5 } Term & High & Moderate & Low & F \\
\hline 1967 & $3.37(54)$ & $2.75(179)$ & $2.91(104)$ & 1.35 \\
1968 & $4.30(46)$ & $5.06(151)$ & $5.01(111)$ & 1.21 \\
1969 & $4.74(38)$ & $4.65(95)$ & $4.98(53)$ & .21 \\
\hline
\end{tabular}

Note: Numbers in parentheses indicate the number of $S s$ on which the mean is based.

Table 2

APQ Category and Mean Experimental Participation

\begin{tabular}{llccc}
\hline & \multicolumn{4}{c}{ APQ Category and Mean Experimental Participation } \\
\cline { 2 - 5 } Term & High & Anxiety Level & Low & F \\
\hline 1967 & $3.86(59)$ & $2.88(154)$ & $2.88(106)$ & $3.82^{*}$ \\
1968 & $6.63(48)$ & $6.17(77)$ & $5.90(20)$ & 1.07 \\
1969 & $6.85(27)$ & $5.61(67)$ & $4.90(20)$ & $4.36^{* *}$ \\
\hline
\end{tabular}

* $p=.02$

$* * p=.01$

Note: Numbers in parentheses indicate the number of Ss on which the mean is based.

normal college populations. In Table $1, S$ s in the three categories are compared on the mean number of experiments in which they participated. No significant differences were observed.

$\mathrm{APQ}$ as a Predictor of Volunteering

In the 1968 and 1969 samples, APQ scores were obtained only from those students who volunteered to take the test. One might expect that these Ss would be more prone to volunteer than those for whom APQ scores were not obtained. Confirming this expectation, it was found that the Ss who took the APQ in the 1968 sample participated in a mean of 6.3 experiments, while those who did not take the test participated in 3.6 experiments $(t=9.15, d f=330, p<.0001)$. In the 1969 sample, those who took the APQ participated in a mean of 5.8 experiments as contrasted with a mean of 3.25 for those who did not take the test $(t=6.48$, df $=195, \mathrm{p}<.0001)$.

If the APQ is a predictor of volunteering, the above fact would lead to the prediction that the mean APQ score of the 1968 and 1969 samples should differ from that of the 1967 sample, which did not take the scale on a voluntary basis. The data revealed that the 1968 and 1969 samples had significantly higher anxiety than did the 1967 sample. The 1968 and 1969 Ss chose a mean of 14.9 onerous alternatives, while the 1967 Ss chose $16.4(t=4.34$, df $=576, p<.0001)$.

Students in each sample were divided into high-, moderate-, and low-anxiety categories on the basis of their APQ scores. High-anxiety Ss were those who chose 19 or more onerous alternatives while low-anxiety Ss chose 12 or less. These criteria identify approximately $25 \%$ of the Ss on each end of the distribution. The mean level of volunteering for each group is presented in Table 2. In both the 1967 and 1969 samples, APQ scores were significantly related to volunteering.

Further inspection of these data indicates that the major portion of the effect was contributed by the high-anxiety Ss. They volinteered significantly more frequently than the moderate and low Ss in the 1967 sample $(t=2.8, d f=317, p=.006)$, in the 1969 sample $(t=2.81, d f=112, p=.006)$, and nonsignificantly more frequently in the 1968 sample $(t=1.38, d f=143, p=.165)$.

\section{DISCUSSION}

Since there was an underrepresentation of nonvolunteers in the 1968 and 1969 APQ samples, the failure to find a significant effect in the 1968 sample is not surprising. In view of this fact, the significant result in the 1969 sample is even more convincing The APQ is a good predictor of the tendency to volunteer for experiments, at least under the conditions present at Dartmouth.

At least two plausible explanations may be offered for the greater volunteering of highly anxious Ss. According to past research (Lykken \& Katzenmeyer, 1968) and anecdotal evidence, Ss identified by the APQ as highly anxious are more willing to comply with societal norms. To the extent that "helping science" is seen as a relevant norm, highly anxious Ss should be more prone to volunteer for experiments. It is also possible that the anxieties of these students include an anxiety about course grades and that participation in experiments is seen as a way to help insure a high grade in the introductory psychology course. The latter hypothesis would suggest that the relationship between $\mathrm{APQ}$ scores and volunteering might not hold if course grades were unaffected by participation.

\section{REFERENCES}

BAREFOOT, J.C. Individual differences in the use of cognitive and physiological cues. Unpublished doctoral dissertation, University of North Carolina, 1967.

BELL, C. R. Personality characteristics of volunteers for psychological studies. British Journal of Social \& Clinical Psychology, 1962, 1, 81-95.

HEILIZER, F. An exploration of the relationship between hypnotizability and anxiety and/or neuroticism. Journal of Consulting Psychology, 1960, 24, 432-436.

HIMELSTEIN, P. Taylor scale characteristics of volunteers and nonvolunteers for psychological experiments. Journal of Abnormal \& Social Psychology, 1956, 52, 138-139.

HOWE, E.S. Quantitative motivational differences between volunteers and nonvolunteers for a psychological experiment. Journal of Applied Psychology, 1960, 44, 115-120.

LATANE, B., \& WHEELER, L. Emotionality and reactions to disaster. Journal of Experimental Social Psychology, 1967, 2, Supplement 1, 95-102.

LYKKEN, D. T. A study of anxiety in the sociopathic personality. Journal of Abnormal \& Social Psychology, 1957, 55, 6-10.

LYKKEN, D. T., \& KATZENMEYER, C. G. Manual for the Activity Preference Questionnaire (APQ). Reports from the Research Laboratories of the Department of Psychiatry, University of Minnesota, 1968, Report No. PR-68-3.

MARTIN, R. M. \& MARCUSE, F. L. Characteristics of volunteers and nonvolunteers for psychological studies. Journal of Consulting Psychology, 1958, 22, 475-479.

ROSEN, E. Differences between volunteers and nonvolunteers for psychological studies. Journal of Applied Psychology, 1951, 35, 185-193.

ROSENTHAL, R. The volunteer subject. Human Relations, 1965, 18, 389-406.

SCHACHTER, S., \& LATANE, B. Crime, cognition, and the autonomic nervous system. In D. Levine (Ed.), Nebraska Symposium on Motivation Lincoln: University of Nebraska Press, 1964. Pp. 221-273.

SCHEIER, I. H. To be or not to be a guinea pig: Preliminary data on anxiety and the volunteer for experiment. Psychological Reports, 1959, 5 . 239-340.

SCHUBERT, D. S. P. Arousal seeking as a motivation for volunteering: MMPI scores and central-nervous-system-stimulant use as suggestive of a trait. Journal of Projective Techniques \& Personality Assessment, 1964, $28,337-340$.

SEIGMAN, A. Responses to a personality questionnaire by volunteers and nonvolunteers to a Kinsey interview. Journal of Abnormal \& Social Psychology, 1956, 52, 280-281.

TAYLOR, J. A. A personality scale of manifest anxiety. Journal of Abnormal \& Social Psychology, 1953, 48, 285-290.

VALINS, S. Emotionality and information concerning internal reactions. Journal of Personality \& Social Psychology, 1967, 6, 458-463. 